\title{
Construção e avaliação do desempenho de três trilhadoras de arroz
}

\author{
José G. da Silva ${ }^{1}$, Pedro M. da Silveira ${ }^{2}$, Luiz C. Barcellos ${ }^{3}$ \& Rogério de A. Almeida ${ }^{3}$ \\ ${ }^{1}$ Embrapa Arroz e Feijão, CP 179, CEP 75375-000, Santo Antônio de Goiás, GO. Fone: (62) 533-2187, Fax: (62) 533-2100. \\ E-mail: jgeraldo@cnpaf.embrapa.br (Foto) \\ 2 Embrapa Arroz e FeijãoFone: (62) 533-2187, Fax: (62) 533-2100 \\ 3 UFG. CP 131, CEP 74001-970, Goiânia, GO
}

Protocolo $016-07 / 02 / 2001$

\begin{abstract}
Resumo: Das operações utilizadas no cultivo do arroz, a colheita é uma das mais importantes, seja por seu elevado custo operacional ou porque reflete na produção e na qualidade do produto. Esta operação demanda grande parte da mão-de-obra destinada à produção em pequenas lavouras nas quais, em geral, o trilhamento é realizado manualmente, batendo-se as plantas num anteparo rígido para o desprendimento dos grãos. Este trabalho teve como objetivo construir e avaliar o desempenho de três trilhadoras em cultivares de arroz de várzea e de terras altas. As trilhadoras são dotadas de fluxo intermitente de plantas, acionadas a pedal ou a motor, e de fluxo contínuo de plantas acionadas a motor. Foram trilhadas plantas compridas e curtas, com grãos com diferentes teores de umidade. A trilhadora de arroz de fluxo intermitente de plantas, acionada por motor, apresentou maior capacidade de trilhamento tendo, portanto, melhor desempenho técnico entre as máquinas ensaiadas. As plantas com colmos curtos, em relação às de colmos compridos, proporcionaram maior rendimento no trilhamento.
\end{abstract}

Palavras-chave: Oryza sativa, colheita, máquina, época de colheita

\section{Construction and performance of three rice threshing machines}

\begin{abstract}
Among all field operations related to the rice crop, harvesting is one of the most important due to its high cost and also because it directly affects grain yield and product quality. Harvesting demands a great portion of the manual labor required in small farms, where the threshing operations are also performed manually by impacting the plants against a hard surface. Mechanical threshing not only improves labor efficiency but also reduces grain breakage during milling. The objective of this study was to develop and evaluate the performance of three machines designed for threshing upland and lowland rice cultivars, using three different operational procedures: intermittent plant feeding, pedal operated; intermittent plant feeding, motor operated; and continuous plant feeding, motor operated. In the trials, long and short stemmed plants were used as well as grains with different moisture contents. The machine using the intermittent plant feeding system with motor operation, showed greater threshing capacity than the other two. Short stemmed plants produced higher threshing yields when compared to the long stemmed ones.
\end{abstract}

Key words: Oryza sativa, harvest, harvesting machinery, harvesting time

\section{INTRODUÇÃO}

Nos sistemas de produção agrícola, a etapa referente à colheita dos grãos é uma das mais importantes, devido ao elevado custo operacional em relação ao custo total de produção e, ainda, por refletir na produção e na qualidade dos produtos. Esta operação demanda cerca de $35 \%$ da mão-deobra utilizada nas pequenas lavouras de arroz (EMATER-MT, 1990).

Segundo Fonseca \& Silva (1997) existem três métodos de colheita de arroz no Brasil: o manual, o semimecanizado e o mecanizado; no primeiro, a ceifa é feita com o auxílio de cutelo de corte liso ou serrilhado e a trilha é realizada em caixotes ou em bancas de madeira e consiste em golpear as panículas até o desprendimento dos grãos; já no método semimecanizado, pelo menos uma das etapas é feita manualmente; em geral, a ceifa e o recolhimento das plantas são manuais, enquanto a trilha é mecânica, por trilhadoras acionadas a trator; enfim, no mecanizado todas as operações são realizadas por meio de máquinas, desde as tracionadas a trator até as colhedoras automotrizes, dotadas de barra de corte de até $9 \mathrm{~m}$ de largura as quais realizam, em seqüência, as operações de corte, recolhimento, trilhamento das plantas e limpeza dos grãos. Conforme Silva (1987) as automotrizes não são acessíveis aos 
pequenos produtores em virtude do elevado preço e da melhor adequação às lavouras maiores.

$\mathrm{Na}$ maioria das pequenas lavouras de arroz de terras altas e de várzeas, o trilhamento é manual, induzindo a uma baixa capacidade de trabalho; além disso, limita a expansão das áreas de cultivo e impede a realização da colheita no momento adequado. A possibilidade de uso de novos equipamentos fabricados com técnicas simples, utilizando-se de recursos de pequenas oficinas, acionados pelas mãos ou pelos pés do homem ou, ainda, por motores de baixa potência, poderá criar condições que permitirão ao pequeno agricultor contornar esses inconvenientes. De acordo com Timóteo Sobrinho (1991) as máquinas trilhadoras estacionárias existentes no mercado brasileiro são, geralmente, de grande ou médio porte, inadequadas para produtores que cultivam menos de 3 ha.

A literatura é escassa de informações sobre equipamentos desenvolvidos para uso nas pequenas lavouras de arroz, principalmente para processamento da colheita. Conforme Fernandes (1993) há muitas décadas o trilhamento mecânico de cereais vem sendo pesquisado e sofrendo modificações continuamente, que visam modernizar o processo, tornando-o mais rápido e eficiente, porém Khan (1972) relata que a introdução de colhedoras automotrizes nos países desenvolvidos tem conduzido ao desaparecimento das máquinas estacionárias para a trilha.

A colheita e o trilhamento do arroz realizados por métodos mecânicos, resultam em grande economia. O trilhamento mecânico do arroz melhora a eficiência da mão-de-obra e reduz os danos no beneficiamento, quando se trabalha com máquinas bem reguladas (Koga, 1979).

Segundo Khan (1972) o Instituto Internacional de Pesquisa de Arroz desenvolveu, nas Filipinas, diversos modelos de trilhadoras de cereais, acionados por motores a gasolina, de baixa potência, portáteis e capazes de aumentar a eficiência da mão-de-obra do pequeno produtor rural. Um desses modelos é a trilhadora japonesa acionada a pedal, que é, segundo Angladette (1969) adequada às pequenas propriedades orizícolas, tanto no plano técnico como no econômico; contudo, apesar das vantagens desse tipo de equipamento, ele ainda não se encontra disponível nas pequenas lavouras de arroz do Brasil.

Silva (1981) desenvolveu um protótipo de uma pequena trilhadora, com a qual avaliou o efeito da velocidade angular do cilindro sobre a eficiência de trilha, a quebra dos grãos e a demanda de potência em arroz de porte alto e de porte baixo. Incrementos de velocidade do cilindro não refletiram significativamente na capacidade de trilhamento nem na perda de grãos por deficiência de degranamento, e a percentagem de grãos quebrados e a demanda de potência cresceram com o aumento da velocidade do cilindro.

As condições em que se encontra a cultura por ocasião da colheita, constituem fatores determinantes no dimensionamento da máquina. Possamai \& Back (1986) verificaram que a umidade elevada no arroz reduz a produção e a eficiência das trilhadoras, requer maior velocidade no cilindro degranador e consome mais potência.

A inexistência, no Brasil, de equipamentos apropriados ao trilhamento do arroz em pequenas propriedades, como trilhadoras acionadas a pedal ou por pequenos motores, é um fato consumado e que merece atenção da pesquisa para desenvolvê-los. Neste sentido, este trabalho teve como objetivo construir e avaliar o desempenho de três diferentes trilhadoras em função de duas alturas de plantas, obtidas no ceifamento manual, e de três épocas de colheita das cultivares Formoso e Caiapó.

\section{MATERIAL E MÉTODOS}

Foram construídas três trilhadoras de arroz, a primeira com fluxo intermitente de plantas e acionamento por pedal, a segunda com fluxo intermitente de plantas e acionamento por motor e a terceira com fluxo contínuo de plantas e acionamento por motor.

\section{Trilhadora de fluxo intermitente de plantas, acionada a pedal $\left(T_{1}\right)$}

Foi construída de acordo com as recomendações de Stout (1966) sendo provida de um cilindro degranador, de uma estrutura de suporte e de um mecanismo de transmissão de movimento ao cilindro (Figura 1A).

O cilindro degranador da trilhadora é constituído de: duas chapas de ferro de $480 \mathrm{~mm}$ de diâmetro, um eixo de ferro de $19,05 \mathrm{~mm}$ (3/4") de diâmetro e $700 \mathrm{~mm}$ de comprimento e de 12 barras transversais de madeira com $490 \mathrm{~mm}$ de comprimento, $65 \mathrm{~mm}$ de largura e $10 \mathrm{~mm}$ de espessura. As barras foram presas às chapas, com parafusos e porcas fixando-se, em uma delas, dez pinos degranadores e, em outra, 11 pinos, de forma que cada pino de uma barra ficasse centralizado entre dois pinos da barra seguinte. Os pinos degranadores foram feitos de arame de aço com $3 \mathrm{~mm}$ de diâmetro, usados na construção de cerca, em formato de " $v$ " e com $50 \mathrm{~mm}$ de altura. O cilindro é apoiado, pelo eixo, em dois mancais montados sobre uma estrutura de metalon $(50 \times 30 \mathrm{~mm})$.

A transmissão de movimentos para o cilindro ocorre por meio de um pedal colocado na parte inferior traseira da máquina, de uma biela de ferro de $320 \mathrm{~mm}$ de comprimento e de duas polias de 250 e de $70 \mathrm{~mm}$ de diâmetro, unidas por uma correia trapezoidal. A máquina possui $800 \mathrm{~mm}$ de comprimento, 700 $\mathrm{mm}$ de largura e $800 \mathrm{~mm}$ de altura e de $43 \mathrm{~kg}$ de massa.

\section{Trilhadora de fluxo intermitente de plantas, acionada a $\operatorname{motor}\left(\mathrm{T}_{2}\right)$}

O desenvolvimento desse equipamento objetivou melhorar a eficiência da degrana e aumentar a capacidade de trilhamento do arroz em relação à trilhadora $T_{1}$. Na sua confecção foi utilizada uma máquina semelhante à trilhadora $\mathrm{T}_{1}$, modificada para receber um motor a gasolina, de 3,5 cv (Figura 1B).

\section{Trilhadora de fluxo contínuo de plantas, acionada a motor $\left(\mathbf{T}_{3}\right)$}

O desenvolvimento dessa trilhadora foi baseado num projeto do IRRI (1979) com o objetivo de melhorar a eficiência da degrana e aumentar a capacidade de trilhamento em relação às trilhadoras $\mathrm{T}_{1} \mathrm{e} \mathrm{T}_{2}$, além de realizar a limpeza dos grãos de arroz. A máquina tem, como componentes principais, um cilindro degranador de dentes, com $710 \mathrm{~mm}$ de comprimento e $305 \mathrm{~mm}$ diâmetro, um côncavo, duas peneiras oscilantes, um ventilador e um motor com potência de $8,0 \mathrm{cv}$ (Figura 1C). 
(A)

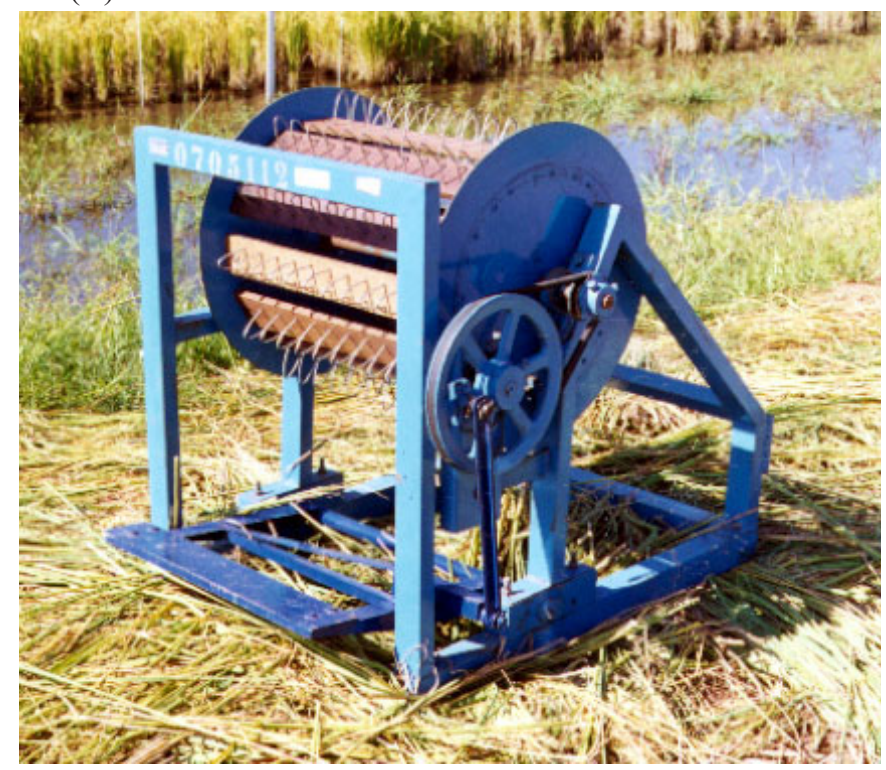

(B)

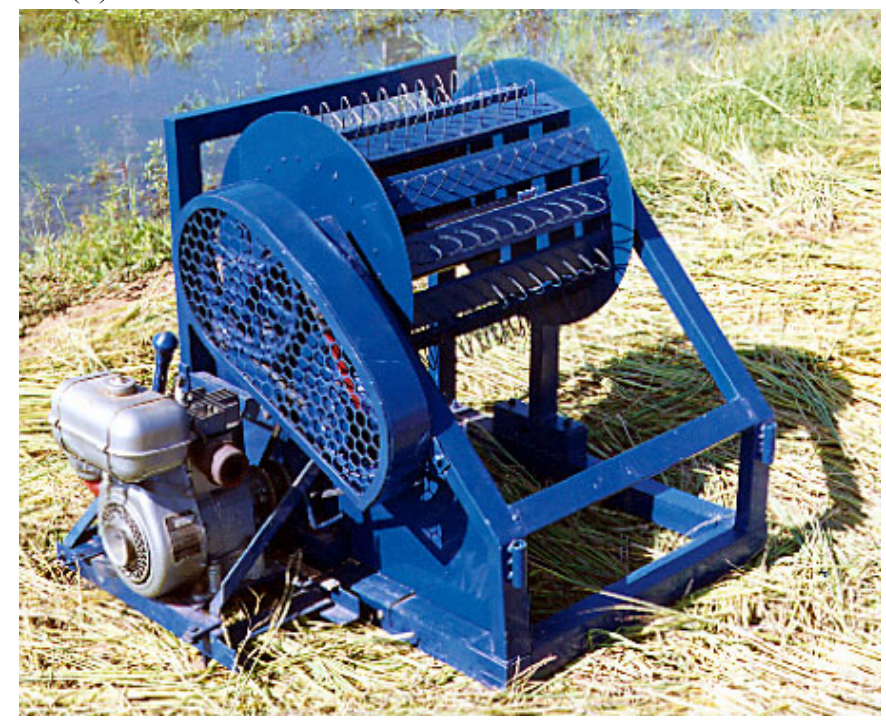

(C)

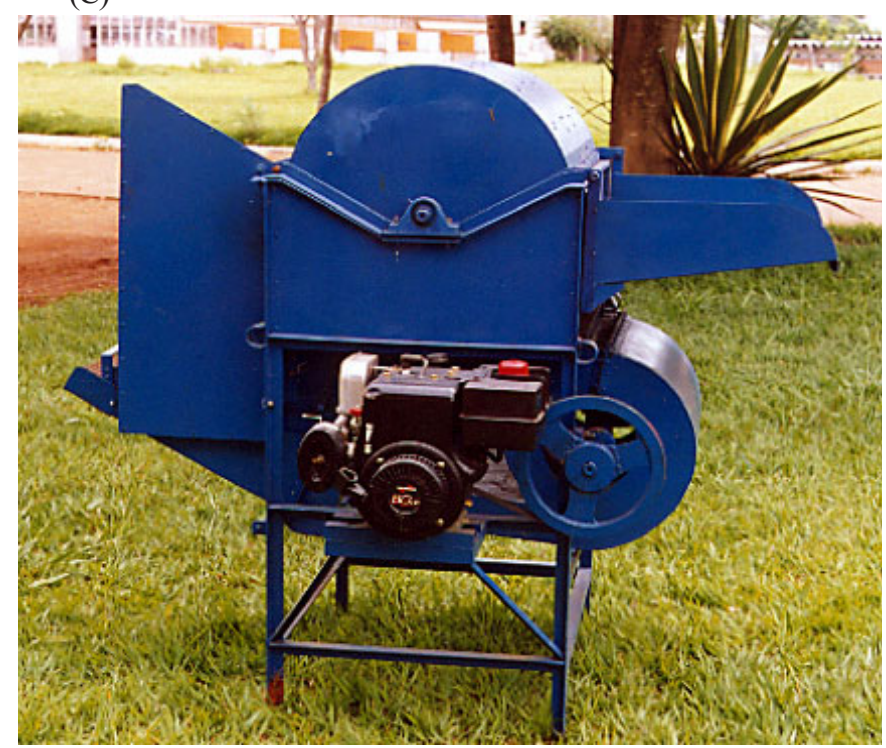

Figura 1. Trilhadora de arroz de fluxo intermitente acionada a pedal (A), de fluxo intermitente acionada a motor (B) e de fluxo contínuo acionada a motor (C)
As três trilhadoras foram operadas por duas pessoas, para proporcionar um trilhamento ritmado das plantas. Na máquina $\mathrm{T}_{1}$ a utilização de dois operários teve também o objetivo de manter uniforme a velocidade do cilindro degranador. Pequenos feixes de plantas de arroz, com cerca de $100 \mathrm{~mm}$ de diâmetro, foram firmemente seguros pela base, próximo ao corte, com as panículas num mesmo lado e aplicados sobre o cilindro degranador em operação das trilhadoras $\mathrm{T}_{1}$ e $\mathrm{T}_{2}$, fazendo-se movimentos de giro para expor todas as panículas sobre o cilindro, até a degrana total observável. Na trilhadora $T_{3}$ os feixes de arroz foram lançados entre o cilindro degranador e o côncavo, para serem trilhados e separados os grãos da palha.

As velocidades médias de rotação dos cilindros degranadores das trilhadoras $\mathrm{T}_{1}, \mathrm{~T}_{2}$ e $\mathrm{T}_{3}$ foram de 326,379 e $620 \mathrm{rpm}$, respectivamente.

A avaliação das três máquinas foi realizada na Embrapa Arroz e Feijão, em Santo Antônio de Goiás, GO, em dois experimentos, um com a cultivar de arroz de várzea Formoso e outro com a cultivar de terras altas Caiapó. O delineamento experimental foi o inteiramente casualizado, com quatro repetições, em esquema fatorial $3 \times 2 \times 3$. Os fatores estudados foram as três trilhadoras, o trilhamento de plantas com dois comprimentos médios depois do ceifamento manual com cutelo $\left(\mathrm{C}_{1}=881 \mathrm{~mm} \mathrm{e}_{2}=760 \mathrm{~mm}\right.$ na 'Formoso' e $\mathrm{C}_{1}=980 \mathrm{~mm} \mathrm{e}$ $\mathrm{C}_{2}=830 \mathrm{~mm}$ na 'Caiapó') e o trilhamento em três épocas de colheita (teores de umidade dos grãos de $\mathrm{E}_{1}=22,1 \%, \mathrm{E}_{2}=15,8 \%$ e $\mathrm{E}_{3}=12,8 \%$ na 'Formoso' e de $\mathrm{E}_{1}=26,0 \%, \mathrm{E}_{2}=17,3 \%$ e $\mathrm{E}_{3}=12,2 \%$ na 'Caiapó'). Cada tratamento de trilhamento teve duração de 10 min. As lavouras de arroz 'Formoso' e 'Caiapó' apresentaram produtividade média de 6.539 e $2.539 \mathrm{~kg} \mathrm{ha}^{-1}$, respectivamente.

Para facilitar a coleta de grãos de arroz trilhados e evitar seu espalhamento, colocaram-se anteparos de lona abaixo e na frente das trilhadoras.

Estabeleceu-se, como capacidade de trilhamento, a massa de grãos de arroz isento de impureza, trilhada em dez min de operação contínua da máquina. Os valores foram transformados em $\mathrm{kg} \mathrm{h}^{-1}$ após serem ajustados para 13\% de umidade nos grãos. Após o trilhamento, cada feixe de arroz foi empilhado sobre uma lona plástica, para se avaliar as perdas e, no final de cada teste, os grãos remanescentes nas panículas foram debulhados manualmente. Assim obtidos, os grãos foram pesados e a quantidade considerada perdida foi expressa em percentagem do total de grãos.

A quantidade de impureza foi avaliada depois da eliminação dos pedaços de colmos maiores, facilmente removíveis dos grãos trilhados. Tomaram-se quatro amostras de grãos para determinar o percentual de impureza presente, em relação à massa de grãos trilhados.

Realizou-se análise de variância para cada parâmetro estudado e, posteriormente, aplicou-se o teste de Tukey, para comparar as médias obtidas.

\section{RESULTADOS E DISCUSSÃO}

A percentagem de impurezas na massa de grãos depois do trilhamento, diferiu significativamente em função do modelo de trilhadora e da época de colheita do arroz, tanto na cultivar Formoso (Tabela 1), quanto na Caiapó (Tabela 2). Na cultivar 
Formoso ocorreu, ainda, diferença significativa nos resultados, em função do comprimento das plantas depois de ceifadas. As percentagens médias de impureza nos grãos trilhados das cultivares Formoso e Caiapó foram, respectivamente, de 3,88 e $4,12 \%$.

Tabela 1. Impureza nos grãos, perda de grãos por deficiência de degrana e capacidade de trilhamento do arroz, em função do modelo de trilhadora, do comprimento das plantas depois de ceifadas e da época de colheita da cultivar de várzea Formoso ${ }^{1}$

\begin{tabular}{cccc} 
Tratamento & $\begin{array}{c}\text { Impureza } \\
(\%)\end{array}$ & $\begin{array}{c}\text { Perda } \\
(\%)\end{array}$ & $\begin{array}{c}\text { Trilhamento } \\
\left(\mathrm{kg} \mathrm{h}^{-1}\right)\end{array}$ \\
\hline
\end{tabular}

\begin{tabular}{lllc} 
Trilhadora & & & \\
$\mathrm{T}_{1}$ & $4,63 \mathrm{~A}$ & $0,57 \mathrm{AB}$ & $168,6 \mathrm{~B}$ \\
$\mathrm{~T}_{2}$ & $4,72 \mathrm{~A}$ & $0,65 \mathrm{~A}$ & $234,7 \mathrm{~A}$ \\
$\mathrm{~T}_{3}$ & $2,29 \mathrm{~B}$ & $0,42 \mathrm{~B}$ & $117,3 \mathrm{C}$ \\
\hline DMS & 0,71 & 0,20 & 19,7 \\
\hline Comprimento & & & \\
$\mathrm{C}_{1}=881 \mathrm{~mm}$ & $4,31 \mathrm{~A}$ & $0,46 \mathrm{~B}$ & $161,6 \mathrm{~B}$ \\
$\mathrm{C}_{2}=760 \mathrm{~mm}$ & $3,46 \mathrm{~B}$ & $0,64 \mathrm{~A}$ & $185,5 \mathrm{~A}$ \\
\hline DMS & 0,48 & 0,14 & 13,4 \\
\hline Época de colheita & & & \\
$\mathrm{E}_{1}=22,1 \%$ & $4,80 \mathrm{~A}$ & $0,65 \mathrm{~A}$ & $155,9 \mathrm{~B}$ \\
$\mathrm{E}_{2}=15,8 \%$ & $3,00 \mathrm{C}$ & $0,46 \mathrm{~A}$ & $169,0 \mathrm{~B}$ \\
$\mathrm{E}_{3}=12,8 \%$ & $3,80 \mathrm{~B}$ & $0,53 \mathrm{~A}$ & $195,7 \mathrm{~A}$ \\
\hline DMS & 0,71 & 0,20 & 19,7 \\
\hline
\end{tabular}

Para cada variável, as médias seguidas pela mesma letra não diferem, pelo teste de Tukey, a 5\% de probabilidade

Teor de umidade nos grãos

Tabela 2. Impureza nos grãos, perda de grãos por deficiência de degrana e capacidade de trilhamento do arroz, em função do modelo de trilhadora, do comprimento das plantas depois de ceifadas e da época de colheita da cultivar Caiapó ${ }^{1}$

\begin{tabular}{llcc}
\hline Tratamento & $\begin{array}{c}\text { Impureza } \\
(\%)\end{array}$ & $\begin{array}{c}\text { Perda } \\
(\%)\end{array}$ & $\begin{array}{c}\text { Trilhamento } \\
\left(\mathrm{kg} \mathrm{h}^{-1}\right)\end{array}$ \\
\hline Trilhadora & & & \\
$\mathrm{T}_{1}$ & $4,41 \mathrm{~A}$ & $1,16 \mathrm{~A}$ & $111,9 \mathrm{~B}$ \\
$\mathrm{~T}_{2}$ & $4,87 \mathrm{~A}$ & $0,91 \mathrm{~A}$ & $150,3 \mathrm{~A}$ \\
$\mathrm{~T}_{3}$ & $3,08 \mathrm{~B}$ & $0,97 \mathrm{~A}$ & $106,3 \mathrm{~B}$ \\
\hline DMS & 0,84 & 0,34 & 16,8 \\
\hline Comprimento & & & \\
$\mathrm{C}_{1}=980 \mathrm{~mm}$ & $4,26 \mathrm{~A}$ & $0,94 \mathrm{~A}$ & $105,1 \mathrm{~B}$ \\
$\mathrm{C}_{2}=830 \mathrm{~mm}$ & $3,98 \mathrm{~A}$ & $1,09 \mathrm{~A}$ & $140,6 \mathrm{~A}$ \\
\hline DMS & 0,57 & 0,22 & 11,4 \\
\hline Época de colheita & & & \\
$\mathrm{E}_{1}=26,0 \%$ & $5,07 \mathrm{~A}$ & $0,97 \mathrm{~A}$ & $119,7 \mathrm{~A}$ \\
$\mathrm{E}_{2}=17,3 \%$ & $3,81 \mathrm{~B}$ & $0,95 \mathrm{~A}$ & $124,8 \mathrm{~A}$ \\
$\mathrm{E}_{3}=12,2 \%$ & $3,47 \mathrm{~B}$ & $1,11 \mathrm{~A}$ & $124,7 \mathrm{~A}$ \\
\hline DMS & 0,84 & 0,34 & 16,8 \\
\hline
\end{tabular}

'Para cada variável, as médias seguidas pela mesma letra não diferem pelo teste de Tukey, a $5 \%$ de probabilidade

Teor de umidade nos grãos

A trilhadora $T_{3}$ proporcionou menor quantidade de impurezas na massa de grãos que as máquinas $\mathrm{T}_{1}$ e $\mathrm{T}_{2}$, cujos resultados foram estatisticamente semelhantes, porque as trilhadoras $\mathrm{T}_{1}$ e $\mathrm{T}_{2}$ não são providas de mecanismo de limpeza dos grãos, como a $\mathrm{T}_{3}$, que possui um ventilador e duas peneiras para retirada de impurezas. Apesar da falta desses mecanismos em $\mathrm{T}_{1}$ e $\mathrm{T}_{2}$, observou-se que o percentual maior de impurezas nos grãos trilhados por essas máquinas, não representava fator de desqualificação do seu desempenho em relação à $T_{3}$, pois as impurezas produzidas eram formadas, na sua grande maioria, de partículas maiores que poderiam ser facilmente removidas da massa de grãos. Essas impurezas maiores eram constituídas de pedaços de colmos que se desprendiam dos feixes de plantas, presos pelas mãos do operador, durante o trilhamento.

$\mathrm{Na}$ cultivar Formoso, as plantas maiores $\left(\mathrm{C}_{1}\right)$ com comprimento médio de $881 \mathrm{~mm}$ depois de ceifadas, produziram mais impurezas nos grãos que as plantas menores $\left(\mathrm{C}_{2}\right) \mathrm{com}$ $760 \mathrm{~mm}$. Resultados semelhantes foram obtidos no trilhamento da cultivar Caiapó, porém neste caso não houve diferença significativa entre os valores de percentagem de impurezas. A maior produção de impurezas em $\mathrm{C}_{1}$ pode estar relacionada ao maior contato dos colmos das plantas, devido ao seu maior comprimento, com o cilindro degranador das máquinas $\mathrm{T}_{1} \mathrm{e} \mathrm{T}_{2}$ e com o cilindro degranador e o côncavo da máquina $T_{3}$.

As épocas de colheita estudadas nas duas cultivares de arroz interferiram no percentual de impurezas dos grãos durante a operação de trilhamento. A época $\mathrm{E}_{1}$, com maior teor de umidade nos grãos, produziu mais impurezas que as épocas $\mathrm{E}_{2}$ e $\mathrm{E}_{3}$, o que pode estar relacionado à maior resistência dos grãos ao trilhamento nesta fase de colheita. Grãos de arroz com maior teor de umidade demandam, geralmente, maior tempo de exposição junto ao cilindro degranador para serem trilhados, o que provoca fragmentação dos colmos das plantas com mais intensidade, elevando, em conseqüência, as impurezas.

Verificam-se efeitos significativos das interações de época de colheita e comprimento das plantas depois de ceifadas, sobre o percentual de impurezas dos grãos nas cultivares de arroz Formoso (Tabela 3), e Caiapó (Tabela 4). A análise dos valores indica que somente na época de colheita $\mathrm{E}_{1}$, com maior teor de umidade dos grãos, as plantas compridas $\left(\mathrm{C}_{1}\right)$ provocaram mais impurezas nos grãos que as curtas $\left(\mathrm{C}_{2}\right)$. Ocorreu produção semelhante de impureza nos grãos, em função das épocas de colheita, no trilhamento de plantas curtas.

Tabela 3. Impureza nos grãos em função do comprimento das plantas depois de ceifadas e da época de colheita da cultivar Formoso $^{1}$

\begin{tabular}{lccc}
\hline \multirow{2}{*}{ Comprimento } & \multicolumn{3}{c}{ Época de colheita $^{2}$} \\
\cline { 2 - 4 } & $\mathrm{E}_{1}=22,1 \%$ & $\mathrm{E}_{2}=15,8 \%$ & $\mathrm{E}_{3}=12,8 \%$ \\
\hline $\mathrm{C}_{1}=881 \mathrm{~mm}$ & $5,84 \mathrm{Aa}$ & $3,15 \mathrm{Ba}$ & $3,92 \mathrm{Ba}$ \\
$\mathrm{C}_{2}=760 \mathrm{~mm}$ & $3,75 \mathrm{Ab}$ & $2,92 \mathrm{Aa}$ & $3,70 \mathrm{Aa}$ \\
\hline DMS (comprimento) & 1,00 & & \\
DMS (Época de colheita) & 0,84 & & \\
\hline
\end{tabular}

${ }^{1}$ Médias seguidas pela mesma letra maiúscula na horizontal e minúscula na vertical não diferem, pelo teste de Tukey, a $5 \%$ de probabilidade

${ }^{2}$ Teor de umidade nos grãos

Tabela 4. Impureza nos grãos, em função do comprimento das plantas depois de ceifadas e da época de colheita da cultivar Caiapó $^{1}$

\begin{tabular}{lccc}
\hline \multirow{2}{*}{ Comprimento } & \multicolumn{3}{c}{ Época de colheita $^{2}$} \\
\cline { 2 - 4 } & $\mathrm{E}_{1}=26,0 \%$ & $\mathrm{E}_{2}=17,3 \%$ & $\mathrm{E}_{3}=12,2 \%$ \\
\hline $\mathrm{C}_{1}=980 \mathrm{~mm}$ & $5,93 \mathrm{Aa}$ & $3,70 \mathrm{Ba}$ & $3,15 \mathrm{Ba}$ \\
$\mathrm{C}_{2}=830 \mathrm{~mm}$ & $4,21 \mathrm{Ab}$ & $3,92 \mathrm{Aa}$ & $3,80 \mathrm{Aa}$ \\
\hline DMS (Comprimento) & 1,18 & & \\
DMS (Época de colheita) & 0,98 & & \\
\hline
\end{tabular}

${ }^{1}$ Médias seguidas pela mesma letra maiúscula na horizontal e minúscula na vertical não diferem, pelo teste de Tukey, a $5 \%$ de probabilidade

${ }^{2}$ Teor de umidade nos grãos 
Na cultivar Formoso a percentagem de perda de grãos remanescentes nas plantas trilhadas, foi influenciada pelo modelo de trilhadora e pelo comprimento das plantas depois de ceifadas. Não se verificaram diferenças significativas entre os valores de perda de grãos em função da época de colheita (Tabela 1), mas na cultivar Caiapó os tratamentos relacionados ao modelo de trilhadoras, ao comprimento das plantas e à época de colheita, não interferiram no percentual de perda de grãos (Tabela 2). As perdas médias de grãos no trilhamento da Formoso e da Caiapó foram, respectivamente, de 0,55 e 1,02\% da produção, bem inferior às verificadas na colheita com colhedoras automotrizes, por Fonseca \& Silva (1997).

Quando operadas na cultivar Formoso, constatou-se tendência das trilhadoras de arroz de fluxo intermitente de plantas $\left(T_{1}\right.$ e $\left.T_{2}\right)$ de produzirem maior percentual de perda de grãos que a trilhadora de fluxo contínuo de plantas $\left(\mathrm{T}_{3}\right)$ devido à menor exposição das plantas sobre os mecanismos degranadores das duas primeiras máquinas; entretanto, os valores obtidos na operação da $T_{1}$ foram estatisticamente semelhantes aos de $T_{2}$ e $T_{3}$, verificando-se diferença significativa apenas entre os valores de $\mathrm{T}_{2}$ e $\mathrm{T}_{3}$, em que $\mathrm{T}_{3}$ proporcionou menor perda de grãos.

Na cultivar Formoso o trilhamento das plantas compridas $\left(\mathrm{C}_{1}\right)$ proporcionou menor percentagem de perda de grãos em relação ao trilhamento de plantas curtas $\left(\mathrm{C}_{2}\right)$. Conforme a análise realizada para o parâmetro percentagem de impureza nos grãos, o maior contato dos colmos compridos com o cilindro degranador das trilhadoras aumentou a eficiência do trilhamento, reduzindo perda de grãos.

A capacidade de trilhamento das trilhadoras diferiu em função do modelo de máquina e do comprimento das plantas depois de ceifadas, tanto na cultivar Formoso quanto na Caiapó. $\mathrm{Na}$ Formoso verificaram-se, também, diferenças significativas entre os valores de capacidade de trilhamento em função da época de colheita. A capacidade média de trilhamento da Formoso e da Caiapó foi, respectivamente, de 173,5 e de $122,9 \mathrm{~kg} \mathrm{~h}^{-1}$ (Tabelas $1 \mathrm{e} 2$ ).

Em ambas as cultivares de arroz, a trilhadora $\mathrm{T}_{2}$ mostrou maior capacidade de trilhamento que as demais máquinas. Operando na cultivar Formoso, a $\mathrm{T}_{2}$ apresentou maior capacidade média de trilhamento $\left(234,7 \mathrm{~kg} \mathrm{~h}^{-1}\right)$ a qual foi cerca de oito vezes superior ao rendimento no trilhamento manual realizado sobre bancas de madeira, obtido em experimento conduzido por Johnson, citado por Stout (1966). A trilhadora $\mathrm{T}_{3}$ ofereceu a menor capacidade de trilhamento, não logrando um dos objetivos da construção da máquina, que foi o de aumentar a capacidade de trilhamento em relação às trilhadoras $\mathrm{T}_{1}$ e $\mathrm{T}_{2}$, o que foi devido ao fluxo contínuo de alimentação de plantas nessa máquina, que demandou maior tempo de trilhamento de cada feixe de plantas que as trilhadoras $\mathrm{T}_{1} \mathrm{e} \mathrm{T}_{2}$, ambas com fluxo de alimentação de plantas intermitente. Os valores obtidos para capacidade de trilhamento de $\mathrm{T}_{1}$ e $\mathrm{T}_{3}$, na cultivar Caiapó, não diferiram estatisticamente entre si.

Plantas de arroz das duas cultivares com menor comprimento depois de ceifadas, proporcionaram maior capacidade de trilhamento, já que, por possuírem a base do colmo mais fina que as plantas compridas, continham, num mesmo feixe, mais grãos, que, por sua vez, proporcionaram maior rendimento no trilhamento.
$\mathrm{Na}$ Formoso, o trilhamento das plantas colhidas na época $\mathrm{E}_{3}$, com menor teor de umidade nos grãos, proporcionou, em relação às plantas colhidas nas épocas anteriores $\mathrm{E}_{1} \mathrm{e} \mathrm{E}_{2}$, maior rendimento das máquinas. Grãos de arroz com menor teor de umidade apresentaram menor resistência ao rompimento do seu pedúnculo, o que facilitou a operação de trilhamento. Apesar da capacidade de trilhamento em $\mathrm{E}_{2}$ ter sido superior a $\mathrm{E}_{1}$ com maior teor de umidade nos grãos, não se verificou diferença estatística entre os valores.

Verificou-se interação significativa da época de colheita com o tipo de trilhadora sobre a capacidade de trilhamento das plantas (Tabela 5); os resultados indicam que apenas a trilhadora $\mathrm{T}_{2}$ mostrou maior rendimento em $\mathrm{E}_{3}$, enquanto as demais trilhadoras não foram afetadas pelas épocas de colheita.

Tabela 5. Capacidade de trilhamento em função do modelo de trilhadora e da época de colheita da cultivar de várzea Formoso ${ }^{1}$

\begin{tabular}{lccc}
\hline \multirow{2}{*}{ Trilhadora } & \multicolumn{3}{c}{ Época de colheita $^{2}$} \\
\cline { 2 - 4 } & $\mathrm{E}_{1}=22,1 \%$ & $\mathrm{E}_{2}=15,8 \%$ & $\mathrm{E}_{3}=12,8 \%$ \\
\hline $\mathrm{T}_{1}$ & $154,5 \mathrm{Ab}$ & $178,4 \mathrm{Ab}$ & $173,1 \mathrm{Ab}$ \\
$\mathrm{T}_{2}$ & $200,9 \mathrm{Ba}$ & $218,9 \mathrm{Ba}$ & $284,3 \mathrm{Aa}$ \\
$\mathrm{T}_{3}$ & $112,4 \mathrm{Ac}$ & $109,7 \mathrm{Ac}$ & $129,7 \mathrm{Ac}$ \\
\hline DMS & 34,08 & & \\
\hline
\end{tabular}

${ }^{1}$ Médias seguidas pela mesma letra maiúscula na horizontal e minúscula na vertical não diferem, pelo teste de Tukey, a $5 \%$ de probabilidade

${ }^{2}$ Teor de umidade nos grãos

\section{CONCLUSÕES}

1. A trilhadora de arroz de fluxo intermitente de plantas, acionada a motor, apresenta maior capacidade de trilhamento que as trilhadoras de fluxo intermitente de plantas acionadas a pedal e de fluxo contínuo de plantas, acionada a motor.

2. O percentual de impurezas nos grãos é menor na operação da trilhadora de fluxo contínuo de plantas, acionada a motor.

3. Nas cultivares de arroz Formoso e Caiapó, as plantas com colmos curtos em relação às de colmos compridos depois de ceifados, proporcionam maior capacidade de trilhamento das máquinas.

4. Na cultivar Formoso, o menor teor de umidade nos grãos propicia maior capacidade de trilhamento das máquinas e, na cultivar Caiapó, o teor de umidade dos grãos não afetou o rendimento das trilhadoras.

5. A análise conjunta dos parâmetros avaliados (impurezas e perda de grãos e capacidade de trilhamento) indica a trilhadora de arroz de fluxo intermitente de plantas, acionada a motor, como a de melhor desempenho técnico entre as máquinas ensaiadas.

\section{LITERATURA CITADA}

Angladette, A. El arroz. Barcelona: Blume, 1969. p.359-406.

EMATER (Cuiabá, MT). Diretrizes técnicas da cultura do arroz. Cuiabá, 1990. 46p. Série Diretrizes Técnicas Arroz, 5.

Fernandes, H.C. Desenvolvimento e avaliação do desempenho de uma máquina trilhadora de feijão. Viçosa: UFV, 1993. 51p. Dissertação Mestrado 
Fonseca, J.R.; Silva, J.G. da. Perdas de grãos na colheita do arroz. 2. ed. rev. atual. Goiânia: EMBRAPA-CNPAF, 1997. 26p. Circular Técnica, 24.

IRRI. IRRI TH7 axial flow thresher: operator's manual. Los Baños, Filipinas, 1979. 15p.

Khan, A.U. El desarollo de maquinaria agrícola em el Instituto International de Investigacion sobre el Arroz. In: Reunion de Expertos en la Mecanizacion de la Producción y la Elaboracion del Arroz, 1971, Paramaribo. Roma: FAO, 1972. p.125-36.

Koga, Y. Prospects and problems in the promotion of industrial manufacturing of rice post-harvest processing machines and equipments in Southeast Asia. Agricultural Mechanization in Asia, Laguna, v.10, n.1, p.37-41, 1979.
Possamai, O.; Back, N. Metodologia de desenvolvimento do projeto de uma trilhadora multi-cereal. In: Congresso Brasileiro de Engenharia Agrícola, 15., 1986, São Paulo. Anais... Botucatu: Sociedade Brasileira de Engenharia Agrícola, 1986. p.9-18.

Silva, J.G. da. Desenvolvimento e avaliação de desempenho de um protótipo de trilhadora de arroz. Viçosa: UFV, 1981.47p. Tese Mestrado

Silva, J.G. da. Características e avaliação de uma ceifadeiraenleiradora de arroz. Goiânia: EMBRAPA-CNPAF, 1987. 13p. Boletim de Pesquisa, 5.

Stout, B.A. Equipo para la producion de arroz. Roma: FAO, 1966. 193p.

Timóteo Sobrinho, A. Desenvolvimento e avaliação de um protótipo de trilhadora de fluxo radial para sorgo. Viçosa: UFV, 1991. 66p. Dissertação Mestrado 